\title{
Modelo Para Análise Do BaLANÇO SOCIAL: o Caso Azaléia
}

Prof. Jayme Marcos Aben Athar Neto ${ }^{1}$

Mestre em Ciências Contábeis pela FAF/UERJ - 2004

jayme@infolink.com.br

\section{RESUMO}

No contexto comercial do século XXI, administrar seus negócios através de uma gestão socialmente responsável é condição indispensável para qualquer organização alcançar o sucesso desejado. Nesse sentido, as empresas adotaram o Balanço Social como forma de divulgar e prestar contas, à sociedade, dos investimentos e das ações praticadas na área social.

Contudo, o Balanço Social sugerido pelo Instituto Brasileiro de Análises Sociais e Econômicas - IBASE apenas evidencia, de forma bruta, os valores investidos pela empresa em ações de caráter social, podendo, com isso, dificultar sua análise, bem como as compreensão e interpretação pelos seus usuários.

Este trabalho desenvolve um modelo para análise de programas de Responsabilidade Social, fundamentado na análise dos índices (quocientes) formados a partir da relação entre indicadores presentes no Balanço Social, e será aplicado na análise do balanço social da empresa Azaléia.

Palavras Chaves: Responsabilidade Social, Balanço Social, Indicadores, Análise.

\section{ABSTRACT}

In the commercial context of the XXI century, managing business through a social responsible measure is an essential condition to any organization to reach the expected success. In a matter of the fact, the companies adopted the social balance as a way to publicize and report to the large society what it had invested and performed in the social area. However the social balance suggested by the Brazilian Institute Of Social And Economical Analysis - IBASE - just evidences the total amount invested, by the company, in the actions of social character. It could, with that, dificult your analysis, comprebension and interpretation from your users. This paper develops a model for analysis of programs of Social Responsibility, based on the analysis of the indices (quotients) formed from the relation between pointers gifts in the social balance, and will be applied in the analysis of the social balance of the company Azaleia.

KEY WORDS: Social Responsibility, Social Balance, Index, Analysis.

1 Sob a orientação do professor Antônio de Araújo Freitas Junior.

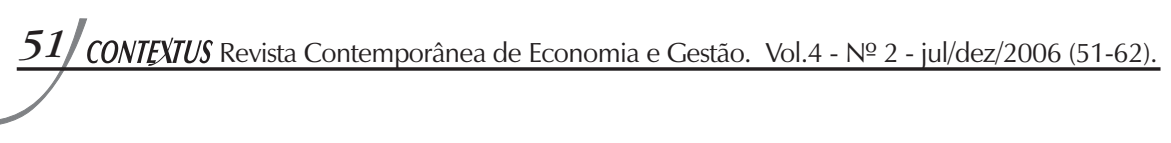




\section{INTRODUÇÃO}

O grande desafio das organizações, nos últimos anos, tem sido suprir as necessidades dos consumidores cada vez mais exigentes. $\mathrm{O}$ bom atendimento ao cliente, a garantia de qualidade dos produtos e serviços e preços competitivos já não bastam para assegurar a sobrevivência de qualquer empresa no mercado competitivo. Tais atributos são necessários, mas não suficientes. É preciso algo mais. $\mathrm{E}$ as empresas, (...), preparam-se para se adequarem ao mais novo paradigma empresarial deste início de século: a empresa com cidadania empresarial. (MELO NETO e FROES, 2001: p. 35)

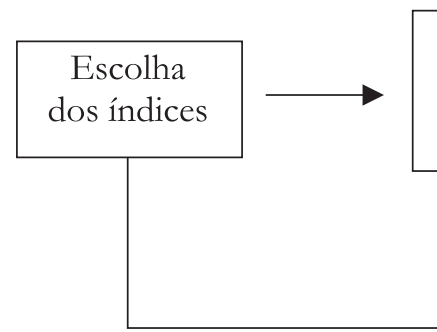

Figura 1: Avaliação

Fonte: elaboração própria

Para se adaptarem a esta nova realidade, as empresas necessitam adotar uma gestão baseada na Responsabilidade Social, onde a prestação de contas de suas ações sociais à sociedade torna-se indispensável.

A gestão da Responsabilidade Social nas empresas, por ser uma área nova e, conseqüentemente, com pouco conhecimento e teorias desenvolvidas, tem suas ações e investimentos evidenciados pelas empresas, apenas, na publicação do Balanço Social acompanhado, ocasionalmente, de um relatório informativo a respeito dos projetos elaborados pela administração.

No Brasil, ainda não há a obrigatoriedade legal da publicação do Balanço Social, sendo mais utilizado pelas empresas o modelo sugerido pelo Instituto Brasileiro de Análises Sociais e Econômicas - IBASE que, além de promover sua publicação, certifica as empresas com o "Selo Balanço Social IBASE/BETINHO".

Entretanto, este modelo exigido pelo IBASE para certificação, apenas evidencia, de forma bruta e sem nenhuma informação adicional, os valores aplicados em cada indicador social constante do balanço, podendo, com isso, dificultar sua análise, bem como a compreensão e interpretação pelos seus usuários.

Partindo desse pressuposto, o objetivo desse trabalho é, através do balanço social da Azaléia, verificar a aplicabilidade dos índices sociais propostos cuja finalidade é analisar os investimentos realizados pela empresa em responsabilidade social.

\section{METODOLOGIA UTILIZADA NA ANÁLISE DO BALANÇO SOCIAL}

$\mathrm{Na}$ análise do balanço social será utilizada uma metodologia semelhante à da análise do balanço financeiro. Para tanto, serão propostos índices sociais criados a partir dos in- dicadores sociais informados no balanço social da empresa. Tais índices serão fundamentados nos quocientes utilizados na análise dos balanços financeiros, que são tidos como os melhores instrumentos para avaliar a saúde financeira das empresas. (IUDÍCIBUS e MARION, 1990: p.110)

Sinteticamente, esta análise obedecerá as seguintes etapas:

Avaliação dos índices de forma intrínseca e ao longo do tempo

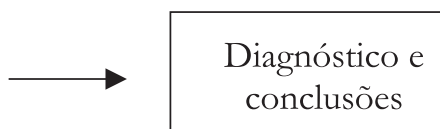

AVALIAÇÃO
Entende-se por avaliação intrínseca dos índices quando se considera, somente, quociente extraído das demonstrações financeiras da própria empresa para avaliar, por exemplo, sua situação financeira, sem que haja uma comparação com índices de outras empresas.

A avaliação intrínseca dos índices é possível, porem limitada e só deixe ser usada quando não se dispõe dê índices-padrão proporcionados pela análise de um conjunto de empresas. (MATARAZZO, 2003: p. 183)

Já a avaliação dos índices ao longo do tempo baseia-se na comparação dos índices de uma empresa com os valores observados nos anos anteriores, revelando-se bastante útil por mostrar tendências seguidas pela empresa. (MATARAZZO, 2003: p. 183)

\section{RESPONSABILIDADE SOCIAL E BALANÇO SOCIAL: UMA BREVE REVISÃO BIBLIOGRÁFICA}

O conceito de Responsabilidade Social Empresarial vem, ao longo do tempo, recebendo muitos significados e interpretações, por se defrontar com áreas limites da ética e da moral, quase sempre fundados em bases subjetivas. Não tem havido muito consenso sobre o significado preciso da Responsabilidade Social, ou o grau de comprometimento da empresa para com a sociedade, surgindo, assim, vertentes de conhecimento que suscitam em teorias e teóricos com conceituações diferentes - Responsabilidade Social como obrigação social (Friedman, 1970); Responsabilidade Social como aprovação social (Davis e Blomstrom, 1975); Responsabilidade Social como abordagem sistêmica dos stakeholders (Zadek, 1998). Neste sentido, Responsabilidade Social é a atuação legítima e voluntária das empresas com a comunidade externa e interna na qual está inserida, ou seja, o envolvimento das 
empresas com atividades e ações que possam contribuir para manter ou aumentar o bem-estar social. (Aligleri e Borinelli, 2001, p. 02)

Responsabilidade Social pode ser também definida como o compromisso que uma organização deve ter para com a sociedade, expresso por meio de atos e atitudes que afetem positivamente, de modo amplo, ou a alguma comunidade, de modo específico, agindo proativamente coerentemente no que tange a seu papel específico na sociedade e a sua prestação de contas para com ela. A organização, nesse sentido, assume obrigações de caráter moral, além das estabelecidas em lei, mesmo que não diretamente vinculadas a suas atividades, mas que possam contribuir para o desenvolvimento sustentável dos povos. Assim, numa visão expandida, a Responsabilidade Social é toda e qualquer ação que possa contribuir para a melhoria da qualidade de vida da sociedade. (Ashley, 2002, p. 06)

Responsabilidade Social incluiria responsabilidades econômicas (produção de bens e serviços dos quais a sociedade necessita a um preço que possa garantir a continuidade dos negócios e a satisfação das obrigações com os investidores), responsabilidades legais (responsabilidade no cumprimento de leis estabelecidas juridicamente), responsabilidades éticas (comportamentos ou atividades que a sociedade espera das empresas e não estão codificados em lei) e responsabilidades filantrópicas (comportamentos e atividades desejados pela sociedade e que são ditados pelos valores empresariais, tendo como exemplo doações e obras beneficentes). Ser socialmente responsável, portanto, implica em maximizar os efeitos positivos sobre a sociedade e minimizar os negativos. (Hawkins e Costa, 2002, p. 04).

Há, na literatura, várias conceituações de Balanço Social. Aqui, apresentamos aquelas consideradas as mais compatíveis com o tema abordado.

(...) um demonstrativo publicado anualmente pela empresa reunindo um conjunto de informações sobre os projetos, benefícios e ações sociais dirigidas aos empregados, investidores, analistas de mercado, acionistas e à comunidade. É também um instrumento estratégico para avaliar e multiplicar o exercício da Responsabilidade Social Corporativa. (IBASE - www.ibase.org.br)

(...) um instrumento de gestão e de informação que visa evidenciar, da forma mais transparente possível, informações econômicas e sociais do desempenho das entidades aos mais diferenciados usuários. (TINOCO, 2002, p. 59)

Em um curto espaço de tempo, houve uma evolução bastante radical nas finalidades do balanço. Partindo do balanço para o proprietário ou gestor da entidade, criado para seu próprio uso, passando para o dos credores, primeiros usuários externos da Contabilidade e, em seguida, do poder tributante (governo), dos investidores, chegando, hoje, ao uso social propriamente dito, na medida em que é utilizado como banco de dados e informações pelo empregados, comunidade e meio ambiente. (PEROTTONI, 2002: p. 52)

A principal função do Balanço Social é tornar pública a Responsabilidade Social da empresa. O Balanço Social, de forma geral e independente, deverá abordar questões que mostrem, com transparência, as informações sobre a atuação social da empresa. Muitos estudiosos do assunto procuram estabelecer critérios para um modelo adequado. É inquestionável, entretanto, que o Balanço Social deverá conter informações sobre recursos humanos, atuação da empresa na comunidade e no meio ambiente e a promoção do bem-estar social. (NEGRA et al, 2002: p. 78)

Para muitos historiadores, a Alemanha é reconhecida como o país iniciante de um esforço para a apresentação de um tipo especial de informação, que teve como nome Balanço Social. Este teve forte influência do movimento trabalhista da década de 20 e de várias correntes filosóficas da Europa. O que possibilitou o início dessas informações foram os movimentos operários da época. (NEGRA et al, 2002: p. 70)

$\mathrm{Na}$ França, organismos patronais e associações profissionais publicam diferentes modelos de tableau de bord social. Observou-se que nesse país, a partir de 1970, as empresas passaram a publicar uma bateria de indicadores sociais, juntamente com os indicadores financeiros tradicionais. Em 1977, a França tornou-se o primeiro país a editar e publicar uma Lei (Lei no .77 .769 du juilllet 1977 relative au bilan social de I'entreprise) obrigando empresas com mais de 300 funcionários evidenciarem suas ações sociais no Balanço Social. (TINOCO, 2002: p. 60).

No Brasil, as primeiras pesquisas sobre Balanço Social sugiram em 1980, baseadas nas experiências de outros países. No meado dos anos 90, intensificaram-se as discussões sobre o Balanço Social e, por decorrência, algumas empresas deram os primeiros passos rumo à elaboração e divulgação dessa nova peça contábil. (ARAÚJO, 2003: p. 84)

A cultura do Balanço Social no Brasil ganhou ênfase somente em 1996, quando uma campanha, encabeçada pelo sociólogo Herbert de Souza, o Betinho, apoiada pelo jornal Gazeta Mercantil e pelo Instituto de Brasileiro de Análises Sociais e Econômicas - IBASE, obteve a adesão de diversas organizações à sua proposta de publicação de um Balanço Social pelas empresas, junto com as demais demonstrações contábeis, com o objetivo de prestar contas do que faziam pela qualidade de vida, tanto dentro, quanto fora da organização.

Em 1998, para estimular a participação de um maior número de corporações, o IBASE lançou o "Selo Balanço Social IBASE/BETINHO”. O Selo é conferido, anualmente, a todas as empresas que publicam o Balanço Social no 
modelo sugerido por essa instituição, dentro da metodologia e dos critérios propostos. Através deste Selo, as empresas podem mostrar - em seus anúncios, embalagens, Balanço Social, sites e campanhas publicitárias - que investem em educação, saúde, cultura, esportes e meio ambiente. Esta certificação demonstra o quanto a empresa está comprometida com a qualidade de vida dos seus colaboradores, comunidade e meio ambiente. (IBASE - www.ibase.org.br)

A seguir, um modelo de exemplo do Balanço Social Proposto pelo IBASE.

Tabela 1: Exemplo de Balanço Social

\section{Balanço Social Anual \\ Empresa:}

1. Base de Calculo

Valor (mil reais)

Receita Líquida (RL)

Resultado Operacional (RO)

Folha de Pagamento Bruta (FPB)

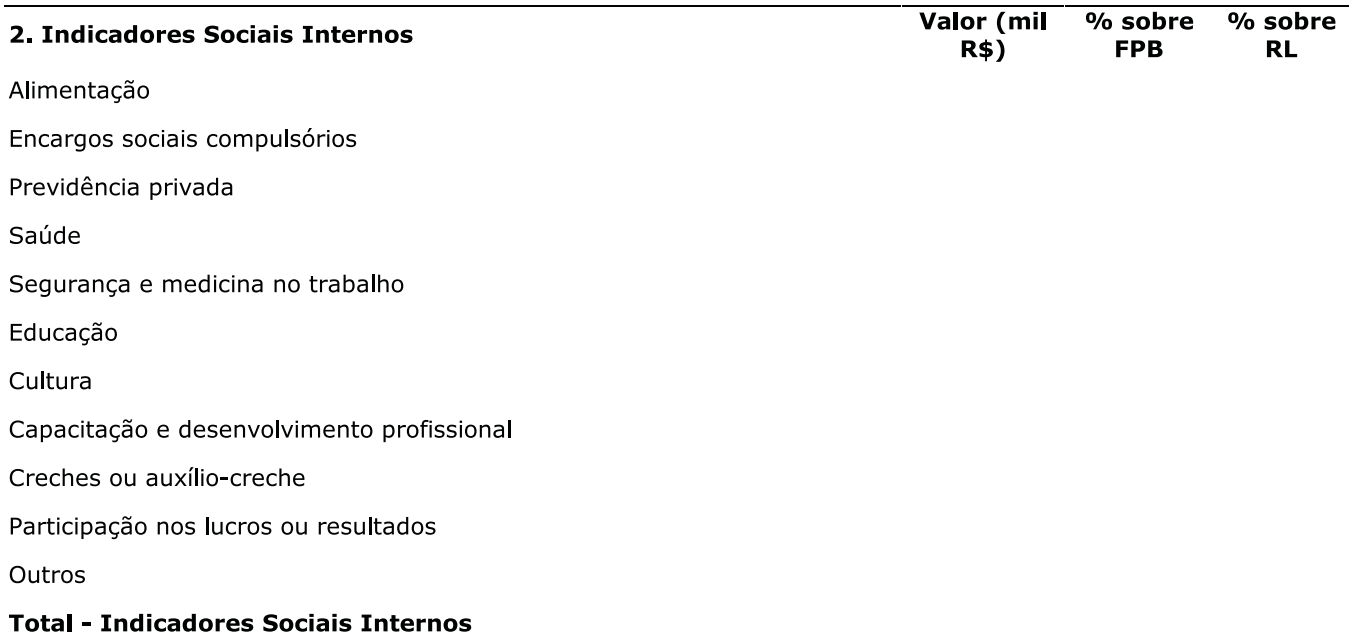

\begin{tabular}{lcc}
\hline 3. Indicadores Sociais Externos & Valor (mil & $\%$ sobre $\%$ sobre \\
R $\$)$ & RO & RL
\end{tabular}

Educação

Cultura

Saúde e saneamento

Habitação

Esporte

Lazer e diversão

Creches

Alimentação

Combate à fome e segurança alimentar

Outros

Total das contribuições para a Sociedade

Tributos (excluídos encargos sociais)

Total Indicadores Sociais Externos

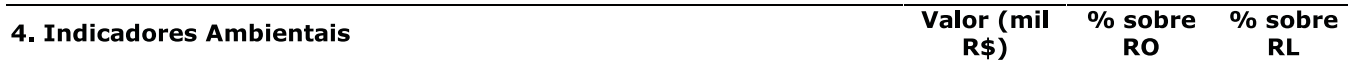

Investimentos relacionados com a produção/operação da empresa

Investimentos em programas e/ou projetos externos

Total dos Investimentos em Meio Ambiente

Quanto ao estabelecimento de metas anuais para minimizar resíduos, o

consumo em geral na produção/operação e aumentar a eficácia na utilização

de recursos naturais, a empresa:

5. Indicadores do Corpo Funcional 
continuação

\author{
5. Indicadores do Corpo Funcional \\ $\mathrm{N}^{\circ}$ de empregados(as) ao final do período \\ No de admissões durante o período \\ $N^{\circ}$ de empregados(as) terceirizados(as) \\ No de estagiários(as) \\ No de empregados(as) acima de 45 anos \\ $N^{\circ}$ de mulheres que trabalham na empresa \\ $\%$ de cargos de chefia ocupados por mulheres \\ $N^{\circ}$ de negros(as) que trabalham na empresa \\ $\%$ de cargos de chefia ocupados por negros(as) \\ No de portadores de deficiência ou necessidades especiais
}

\title{
6. Informações relevantes quanto ao
} exercício da cidadania empresarial

Relação entre a maior e a menor

remuneração da empresa

Número total de acidentes de trabalho

Os projetos sociais ambientais

desenvovidos pela empresa foram

definidos por:

Os padrões de segurança e salubridade no

ambiente de trabalho foram definidos por:

Quanto à liberdade sindical, ao direito de

negociação coletiva e à representação

interna dos(as) trabalhadores(as), a

empresa:

A previdência privada contempla:

A participação nos lucros ou resultados

contempla:

Na seleção dos fornecedores, os mesmos

padrões éticos e de responsabilidade social

e ambiental adotados pela empresa:

Quanto à participação dos empregados(as)

em programas de trabalho voluntário, a

empresa:

Número ções e críticas de

consumidores(as):

$\%$ de reclamações e críticas solucionadas:

Valor adicionado total a distribuir (em mil

$\mathrm{R} \$)$ :

Distribuição do Valor Adicionado (DVA):

\section{Fonte: IBASE}

\section{OS BENEFICIÁRIOS}

\section{DA ANÁLISE DO BALANÇO SOCIAL}

As demonstrações financeiras de uma organização são peças que se propõem apenas a compilar e organizar dados relativos aos seus eventos operacionais. Tais dados, somente dispostos de acordo com as normas contábeis, não transmitem todas as informações necessárias para satisfazer as necessidades de entendimento e interpretação de seus usuários. Para minimizar este problema e proporcionar um melhor entendimento e credibilidade das demonstrações financeiras, a Contabilidade adotou, dentre outras, a técnica de análise de balanços e auditoria, além das notas explicativas cuja finalidade é complementar as demonstrações financei- ras com informações que tornem ainda mais transparentes seus dados.

Atualmente, os stakeholder dispõem, apenas, dos dados divulgados no Balanço Social para obterem informações sobre as ações de Responsabilidade Social da empresa. Todavia, este padrão de balanço, proposto pelo IBASE, carece de maiores informações que possibilitem um entendimento mais apurado dos dados nele evidenciados.

Da mesma forma que a análise das demonstrações financeiras permite ao usuário concluir se uma empresa merece, ou não, crédito, tem, ou não, condições de pagar uma dívida e se suas ações serão, ou não, rentáveis; a análise do Balanço Social, ao proporcionar maior transparência e esclarecimento dos seus dados, facilitará o entendimento a interpretação 
dos indicadores sociais, possibilitando ao usuário deduzir, por exemplo, se uma empresa investe o suficiente em questões ambientais para evitar acidentes com o meio ambiente ou em capacitação e desenvolvimento profissional de seus colaboradores, visando a excelência técnica de seu corpo funcional.

$\mathrm{O}$ rol a seguir elenca alguns usuários da análise do $\mathrm{Ba}-$ lanço Social e quais informações podem ser úteis a eles.

FORNECEDOR / CONSUMIDOR - Auxiliar na evidenciação da política de Responsabilidade Social adotada pela empresa, valendo-se da análise dos índices propostos neste trabalho, tendo em vista que somente os valores brutos apresentados em seu Balanço Social podem não ser suficientes para propiciar aos usuários o entendimento desejável sobre os investimentos. Para estes usuários, o importante é obter informações que os certifiquem da manutenção de suas relações comerciais (compra e venda de produtos e serviços) com empresas que atuem com ética e Responsabilidade Social perante seus stakeholder.

GOVERNO - Proporcionar, através da análise do Balanço Social, uma visão macro dos investimentos sociais realizados pelas empresas, norteando, dessa forma, o poder publico a investir em políticas que venham complementar as ações sociais realizadas pela iniciativa privada, tornandose, com isto, verdadeiro parceiro social das empresas. Outro dado constante no Balanço Social, que é de interesse do governo, são os impostos e contribuições recolhidos pelas empresas e destacados nesta Demonstração.

COLABORADORES - Subsidiar estes usuários, com informações necessárias para um melhor entendimento da política de recursos humanos implementada pela empresa, assim como o critério utilizado por ela para a distribuição dos recursos nos indicadores sociais internos, tais como: capacitação profissional, saúde, etc.

Porém, o mais importante para o colaborador é saber que pertence ao corpo funcional de uma organização que prime por um relacionamento transparente, ético e socialmente responsável com seus stakeholders.

SOCIEDADE - Evidenciar os benefícios sociais diretos trazidos pela empresa e esclarecer se o montante de investimentos nos indicadores sociais externos está condizente com a necessidade social daquela sociedade. A Relação dos Indicadores Sociais Externos (RISE) apresentada neste trabalho poderá ser fonte de informação para este fim.

\section{5. ÍNDICES (QUOCIENTES) DE ANÁLISE DO BALANÇO SOCIAL}

São índices (quocientes) calculados a partir da relação entre os grupos de indicadores do Balanço Social, sendo indispensáveis na análise do balanço social de acordo com a metodologia proposta para tal. Com isso, espera-se interpretar, mais facilmente, dentre outras, a forma de distribuição dos recursos aplicados nos indicadores sociais (interno, externo e ambiental) pela empresa, uma vez que tais recursos são evidenciados, apenas, de forma bruta no Balanço Social da empresa.

Se a política social da empresa estiver orientada no sentido de aplicar mais recursos em Responsabilidade Social Interna, por exemplo, isto será evidenciado pelo aumento do índice que registra a relação entre o montante dos recursos investidos nos indicadores sociais internos e o total aplicado em Responsabilidade Social.

Porém, para uma cuidadosa análise de um Balanço Social deve-se estudá-lo como um todo, inclusive a evolução dos indicadores de caráter social.

Para exemplificar a aplicação prática dos índices propostos foram utilizados dados do Balanço Social da empresa Calçados Azaléia S/A, referentes ao exercício de 2001, 2002 e 2003. Estes dados estão disponíveis no site www.ibase.com.br.

\subsection{Grau de participação da receita líquida de vendas (gprv)}

Relaciona a receita líquida de vendas com o total aplicado em investimentos sociais, indicando quanto a empresa investiu em Responsabilidade Social para cada R \$1,00 de receita líquida de vendas obtida no período base.

Índice 1: $\begin{gathered}\text { Indicadores Sociais Internos }+ \\ +\end{gathered}$
$\begin{gathered}\text { Indicadores Sociais Externos } \\ + \text { Indicadores Ambientais }\end{gathered}$
Receita Líquida de Vendas

\subsection{Grau de participação do resultado operacional (gpro)}

Evidencia a relação entre o resultado obtido pela empresa e o montante investido em Responsabilidade Social num determinado exercício.

$\mathrm{Na}$ análise tradicional de balanços, o quociente estabelecido entre o lucro e qualquer outro indicador, nos revela um grau de rentabilidade, ou seja, o retorno econômico-financeiro proporcionado pelo investimento neste indicador. Porém, quando se trata de análise de investimentos sociais, ainda, não há estudos suficientes que possam medir quanto de retorno é obtido devido aos investimentos realizados em Responsabilidade Social.

\begin{tabular}{cc} 
Índice 2: & Resultado Operacional \\
\hline Indicadores Sociais Internos + \\
+ Indicadores Sociais Externos + \\
+ Indicadores Ambientais
\end{tabular}

No entanto, o modelo de análise proposto considera que o montante de recursos aplicados em Responsabilidade Social deve ter metas estabelecidas pela política de Responsabilidade Social e não, necessariamente, guardar uma relação com o montante dos indicadores que compõem a base de cálculo do Balanço Social - receita líquida e lucro operacional. 
Tabela 2: Participação do Resultado Operacional

\begin{tabular}{|l|c|c|c|}
\cline { 2 - 4 } \multicolumn{1}{c|}{} & $\mathbf{2 0 0 1}$ & $\mathbf{2 0 0 2}$ & $\mathbf{2 0 0 3}$ \\
\hline $\begin{array}{l}\text { Total } \\
\text { de Investimento Social }\end{array}$ & 114.554 & 135.963 & 131.488 \\
\hline $\begin{array}{l}\text { Receita } \\
\text { Líquida (RL) }\end{array}$ & 620.429 & 612.578 & 622.420 \\
\hline $\begin{array}{l}\text { Resultado } \\
\text { Operacional (RO) }\end{array}$ & 49.065 & 80.359 & 9.484 \\
\cline { 2 - 4 } & $\mathbf{2 0 0 1}$ & $\mathbf{2 0 0 2}$ & $\mathbf{2 0 0 3}$ \\
\hline \multicolumn{1}{|l|}{18,46} & 22,20 & 21,13 \\
\hline Ínice 01 & 42,83 & 59,10 & 7,21 \\
\hline Índice 02 & \multicolumn{2}{|c}{} \\
\hline
\end{tabular}

Fonte: Elaboração Própria

\subsection{Grau de participação dos indicadores sociais - - internos, externos e ambientais (gpis)}

Estes índices relacionam os investimentos nos três grupos de indicadores sociais (interno, externo e ambiental) com o montante de recursos aplicado em Responsabilidade Social, evidenciando a proporção de investimentos destinados a cada grupo analisado.

Índice 3:

Indicadores Sociais Internos

Indicadores Sociais Internos +

+ Indicadores Sociais Externos +

+ Indicadores Ambientais

Índice 4:

Indicadores Sociais Externos

Indicadores Sociais Internos +

+ Indicadores Sociais Externos +

+ Indicadores Ambientais

Índice 5:

Indicadores Ambientais

Indicadores Sociais Internos +

+ Indicadores Sociais Externos +

+ Indicadores Ambientais

Tabela 3: Grau de Participação dos Indicadores Sociais

\begin{tabular}{|l|r|r|r|r|}
\cline { 2 - 5 } \multicolumn{1}{c|}{} & \multicolumn{1}{c|}{$\mathbf{2 0 0 1}$} & $\mathbf{2 0 0 2}$ & $\mathbf{2 0 0 3}$ & \multicolumn{1}{c|}{ TOTAL } \\
\hline $\begin{array}{l}\text { Indicadores } \\
\text { Sociais Internos (ISI) }\end{array}$ & 62.032 & 66.224 & 68.775 & $\mathbf{1 9 7 . 0 3 1}$ \\
\hline $\begin{array}{l}\text { Indicadores } \\
\text { Sociais Externos (ISE) }\end{array}$ & 51.647 & 67.774 & 61.118 & $\mathbf{1 8 0 . 5 0 9}$ \\
\hline $\begin{array}{l}\text { Indicadores Sociais } \\
\text { Ambientais (ISA) }\end{array}$ & 875 & 1.995 & 1.595 & $\mathbf{4 . 5 0 9}$ \\
\hline TOTAL & 114.554 & 135.963 & 131.488 & $\mathbf{3 8 2 . 0 0 5}$ \\
\cline { 2 - 5 } & $\mathbf{2 0 0 1}$ & $\mathbf{2 0 0 2}$ & $\mathbf{2 0 0 3}$ \\
\hline Índice 3 & \multicolumn{2}{|c|}{54,15} & 48,70 & 52,31 \\
\hline Índice 4 & 45,09 & 49,83 & 46,48 \\
\hline Índice 5 & 0,76 & 1,47 & 1,21 \\
\hline
\end{tabular}

Fonte: Elaboração Própria

\subsection{Relação dos indicadores sociais internos (risi)}

Indicam a composição dos recursos aplicados exclusivamente em Responsabilidade Social Interna. Os índices 6 e 7 revelam, respectivamente, o percentual de participação dos indicadores laborais (indicadores compulsórios) e, complementarmente, da remuneração indireta, em relação ao montante investido em indicadores internos.

$O$ fato de o índice 6 ser elevado pode significar, a princípio, que os recursos investidos neste grupo do Balanço Social estão, em sua maioria, alocados para cumprimento das obrigações legais (encargos sociais compulsórios e participação nos lucros) e dos projetos discricionários (capacitação profissional, saúde, educação, etc) carentes de investimentos.

Índice 6:

Indicadores Laborais

Indicadores Sociais Internos

Índice 7:

Remuneração Indireta

Indicadores Sociais Internos

Tabela 4: Relação dos Indicadores Sociais Internos

\begin{tabular}{|c|c|c|c|}
\hline & 2001 & 2002 & 2003 \\
\hline Indicadores Laborais & 41.961 & 41.777 & 44.206 \\
\hline Remuneração Indireta & 20.071 & 24.447 & 24.569 \\
\hline \begin{tabular}{|l|} 
Indicadores \\
Sociais Internos
\end{tabular} & 62.032 & 66.224 & 68.775 \\
\hline & 2001 & 2002 & 2003 \\
\hline Índice 6 & 67,64 & 63,08 & 64,28 \\
\hline Índice 7 & 32,36 & 36,92 & 35,72 \\
\hline
\end{tabular}

Fonte: Elaboração Própria

\subsection{Relação dos indicadores sociais externos (rise)}

Indicam a composição dos recursos aplicados exclusivamente em Responsabilidade Social Externa. As relações dos índices 8 e 9 revelam, respectivamente, o percentual da participação compulsória em recolhimentos de tributos e, complementarmente, dos investimentos voluntários em programas sociais visando o bem estar da sociedade, em relação ao montante investido em Responsabilidade Social Externa.

O índice 8 elevado pode evidenciar que os recursos divulgados neste grupo do Balanço Social estão, em sua maioria, direcionados ao pagamento de tributos (obrigação legal), revelando, portanto, uma baixa participação efetiva e direta da empresa em ações sociais perante a sociedade. 
Índice 8:

Tributos (excluídos encargos sociais)

$$
\text { Indicadores Sociais Externos }
$$

Índice 9:

$$
\text { Contribuições Para a Sociedade }
$$

Indicadores Sociais Externos

\begin{tabular}{|c|c|c|c|}
\hline & 2001 & 2002 & 2003 \\
\hline Total de Tributos Pagos & 49.337 & 65.061 & 59.074 \\
\hline Contribuições para Sociedade & 2.310 & 2.683 & 2.044 \\
\hline Indicadores Sociais Externos & 51.647 & 67.744 & 61.118 \\
\hline & 2001 & 2002 & 2003 \\
\hline Índice 8 & 95,53 & 96,04 & 96,66 \\
\hline Índice 9 & 4,47 & 3,96 & 3,34 \\
\hline
\end{tabular}

Tabela 5: Relação dos Indicadores Sociais Externos

Fonte: Elaboração Própria

\subsection{Relação dos indicadores sociais ambientais (RISA)}

Indicam a composição dos recursos aplicados exclusivamente no meio ambiente. Os índices 10 e 11 evidenciam, respectivamente, o percentual de investimentos realizados pela empresa visando minimizar os riscos, ao meio ambiente, causados pela sua operacionalização e, complementarmente, o percentual de recursos investidos em projetos não restritos às necessidades ambientais locais - financiamento de programas de despoluição, desmatamento, entre outros, não necessariamente ligados a sua produção.

Para investidores é de grande valia, pois poderão indicar o possível risco a que seu capital investido na empresa está submetido, considerando uma desvalorização acionária conseqüente de um acidente ecológico causado, por exemplo, pela falta de infra-estrutura adequada à operacionalização da empresa.

O fato de o índice 10 ser elevado pode significar, em princípio, que os recursos investidos neste grupo do Balanço Social visam, em sua maioria, proteger, somente, o meio ambiente local de possíveis danos causados pelo processo operacional da empresa, revelando, portanto, pouca participação em outros projetos ambientais.

Índice 10:

Investimentos Relacionados com a Produção

Investimento Total em Meio Ambiente

Índice 11:

Investimentos em Programas Externos

Investimento Total em Meio Ambiente

\begin{tabular}{|c|c|c|c|}
\hline & 2001 & 2002 & 2003 \\
\hline Investimentos na Produção & 863 & 1.995 & 1.595 \\
\hline Projetos Externos & 12 & 0 & 0 \\
\hline \multirow[t]{2}{*}{ Indicadores Sociais Internos } & 875 & 1.995 & 1.595 \\
\hline & 2001 & 2002 & 2003 \\
\hline Índice 10 & 98,63 & 100 & 100 \\
\hline Índice 11 & 1,37 & 0 & 0 \\
\hline
\end{tabular}

Tabela 6: Relação dos Indicadores Sociais Ambientais

Fonte: Elaboração Própria

\subsection{Relação dos indicadores compulsórios e voluntários}

Entende-se por indicadores compulsórios aqueles que revelam no que as empresas são obrigadas a investir, independente de manter uma política de Responsabilidade Social. No Balanço social proposto pelo IBASE, temos: encargos sociais, participação nos lucros e resultados e tributos (excluídos encargos sociais).

Índice 12:

Indicadores Sociais Compulsórios

Total do Investimento Social

Índice 13:

Indicadores Sociais Voluntários

Total do Investimento Social

\begin{tabular}{|c|c|c|c|}
\hline & 2001 & 2002 & 2003 \\
\hline Total de Investimento Social & 114.554 & 135.963 & 131.4 \\
\hline $\begin{array}{l}\text { Indicadores Sociais } \\
\text { Compulsórios }\end{array}$ & 91.298 & 106.838 & $103.2 i$ \\
\hline $\begin{array}{l}\text { Indicadores Sociais } \\
\text { Voluntários }\end{array}$ & 23.256 & 29.125 & 28.21 \\
\hline & 2001 & 2002 & 2003 \\
\hline Índice 12 & 79,70 & 78,58 & 78,55 \\
\hline Índice 13 & 20,30 & 21,42 & 21,45 \\
\hline
\end{tabular}

Tabela 7: Relação dos Indicadores Compulsórios e Voluntários

Fonte: Elaboração Própria

\subsection{Relação dos indicadores laborais (ril)}

Evidencia a relação dos indicadores laborais com o resultado econômico obtido pela empresa.

Sua análise interessa, principalmente, aos colaboradores e sindicatos, podendo ser utilizada, por exemplo, para as negociações do dissídio coletivo de trabalho. 
Índice 13:

Folha de Pagamento Bruta

Total do Investimento Social

Índice 15:

Participação nos Lucros

Resultado Operacional

Tabela 8: Relação dos Indicadores Laborais

\begin{tabular}{|l|c|c|c|}
\cline { 2 - 4 } \multicolumn{1}{c|}{} & $\mathbf{2 0 0 1}$ & $\mathbf{2 0 0 2}$ & $\mathbf{2 0 0 3}$ \\
\hline $\begin{array}{l}\text { Folha de Pagamento } \\
\text { Bruta (FPB) }\end{array}$ & 114.456 & 126.989 & 137.053 \\
\hline $\begin{array}{l}\text { Receita Líquida de } \\
\text { Vendas (RLV) }\end{array}$ & 620.429 & 612.578 & 622.420 \\
\hline
\end{tabular}

\begin{tabular}{|l|c|c|c|}
\cline { 2 - 4 } \multicolumn{1}{c|}{} & $\mathbf{2 0 0 1}$ & $\mathbf{2 0 0 2}$ & $\mathbf{2 0 0 3}$ \\
\hline Índice 14 & 18,45 & 20,73 & 22,02 \\
\hline
\end{tabular}

\begin{tabular}{|l|c|c|c|}
\cline { 2 - 4 } \multicolumn{1}{c|}{} & $\mathbf{2 0 0 1}$ & $\mathbf{2 0 0 2}$ & $\mathbf{2 0 0 3}$ \\
\hline $\begin{array}{l}\text { Participação nos Lucros } \\
\text { (PLR) }\end{array}$ & 9.839 & 5.576 & 2.852 \\
\hline $\begin{array}{l}\text { Resultado Operacional } \\
\text { (RO) }\end{array}$ & 49.065 & 80.359 & 9.484 \\
\cline { 2 - 4 } & $\mathbf{2 0 0 1}$ & $\mathbf{2 0 0 2}$ & $\mathbf{2 0 0 3}$ \\
\hline
\end{tabular}

Fonte: Elaboração Própria

Tabela 9: Relação do Corpo Funcional

\begin{tabular}{|l|r|r|r|}
\hline & 2001 & 2002 & 2003 \\
\hline média de empregados no período & $\mathbf{1 4 . 6 1 8}$ & $\mathbf{1 5 . 4 3 7}$ & $\mathbf{1 5 . 3 6 3}$ \\
\hline saúde & $\mathrm{R} \$ 2.633 .000$ & $\mathrm{R} \$ 3.663 .000$ & $\mathrm{R} \$ 3.644 .000$ \\
\hline média percápita em saúde & $\mathbf{R} \mathbf{1 8 0}$ & $\mathbf{R} \mathbf{2 3 7}$ & $\mathbf{R} \mathbf{2 3 7}$ \\
\hline capacitação e desenvolvimento & $\mathrm{R} \$ 2.171 .000$ & $\mathrm{R} \$ 3.278 .000$ & $\mathrm{R} \$ 2.327 .000$ \\
\hline média percapita em capacitação & $\mathbf{R} \mathbf{1 4 9}$ & $\mathbf{R} \mathbf{2 1 2}$ & $\mathbf{R} \$ 151$ \\
\hline educação & $\mathrm{R} \$ 1.488 .000$ & $\mathrm{R} \$ 2.134 .000$ & $\mathrm{R} \$ 1.560 .000$ \\
\hline média percapita em educação & $\mathbf{R} \$ \mathbf{1 0 2}$ & $\mathbf{R} \mathbf{1 3 8}$ & $\mathbf{R} \$ 102$ \\
\hline
\end{tabular}

\begin{tabular}{|r|r|r|r|}
\cline { 2 - 4 } \multicolumn{1}{c|}{} & $\mathbf{2 0 0 1}$ & $\mathbf{2 0 0 2}$ & $\mathbf{2 0 0 3}$ \\
\hline admissão & 4.278 & 2.471 & 5.135 \\
\hline demissão & 2.577 & 2.534 & 5.220 \\
\hline
\end{tabular}

Fonte: Elaboração Própria

Tabela 10: Indicadores do Valor Adicionado

\begin{tabular}{|l|c|c|}
\hline \multicolumn{3}{|c|}{$\mathbf{2 0 0 1}$} \\
\hline INDICADORES & VALOR (R\$) & \% de PARTICIPAÇ̃̃̃ \\
\hline colaboradores & 176.490 & 55 \\
\hline terceiros & 58.863 & 18 \\
\hline governo & 49.323 & 15 \\
\hline acionista & 36.659 & 11 \\
\hline lucros retidos & 4.232 & 1 \\
\hline TOTAL & 325.567 & 100 \\
\hline
\end{tabular}

\begin{tabular}{|l|c|c|}
\hline \multicolumn{3}{|c|}{$\mathbf{2 0 0 2}$} \\
\hline INDICADORES & VALOR (R\$) & \% de PARTICIPAÇÃO \\
\hline colaboradores & 193.400 & 49 \\
\hline governo & 65.069 & 17 \\
\hline terceiros & 60.671 & 15 \\
\hline acionista & 54.780 & 14 \\
\hline lucros retidos & 18.771 & 5 \\
\hline TOTAL & 392.691 & 100 \\
\hline
\end{tabular}

\begin{tabular}{|l|c|c|}
\hline \multicolumn{3}{|c|}{$\mathbf{2 0 0 3}$} \\
\hline INDICADORES & VALOR (R\$) & \% de PARTICIPAÇÃO \\
\hline colaboradores & 177.247 & 56 \\
\hline governo & 87.847 & 28 \\
\hline terceiros & 42.292 & 13 \\
\hline acionista & 9.409 & 3 \\
\hline lucros retidos & 0 & 0 \\
\hline TOTAL & 316.950 & 100 \\
\hline
\end{tabular}

Fonte: Elaboração Própria

\section{ANÁLISE DOS INDICADORES DE CARÁTER ECONÔMICO}

Entende-se por indicadores de caráter econômico aqueles que venham expressar recursos aplicados pela empresa em seu programa de Responsabilidade Social e divulgados no Balanço Social, através dos seguintes grupos: base de cálculo, indicadores sociais internos, indicadores sociais externos, indicadores ambientais e indicadores do valor adicionado.

A política social desenvolvida pelo Grupo Calçados Azaléia fundamenta-se no exercício das duas dimensões da Responsabilidade Social: gestão da Responsabilidade Social Interna e gestão da Responsabilidade Social Externa (sociedade e meio-ambiente) durante o período, investiu-se um montante de $\mathrm{R} \$$ 382,0 milhões.

Os recursos investidos em ações de Responsabilidade Social Interna ( $\$$ 197,0 milhões) representam 51,58\%, em média, do montante total ( $\mathrm{R} \$ 382,0$ milhões) investido pela empresa durante o período analisado.

Dos indicadores sociais, de remuneração indireta, sugeridos pelo Balanço Social, somente, previdência privada e cultura não receberam investimentos, os demais guardam uma relação de equilíbrio entre eles, evidenciando que a gestão social da empresa procura diversificar, de forma igualitária e coerente, os recursos financeiros aplicados nestes indicadores.

Os indicadores laborais, que são investimentos obrigatórios, representam $64,94 \%$ em média, do montante total investido em Responsabilidade Social Interna. A quantia R\$ 127,9 milhões aplicada nestes indicadores compulsórios evidencia, apenas, o cumprimento das obrigações legais.

De acordo com os números do Balanço Social, a responsabilidade Social Externa é a segunda área que mais con-

59/ CONTEXTUS Revista Contemporânea de Economia e Gestão. Vol.4 - № 2 - jul/dez/2006 (51-62). 
centra recursos de investimentos sociais ( $\mathrm{R} \$ 180,5$ milhões), cerca de 47,3\%, em média, durante o período analisado.

Os recursos sociais externos representam os investimentos na comunidade e são compostos pelas contribuições para a sociedade (indicadores voluntários) e pelos tributos, excluídos os encargos sociais (indicadores compulsórios). A proporcionalidade mantida entre estes indicadores (contribuições para a sociedade, 3,9\% em média - tributos, 96,1\% em média) revela que os investimentos em Responsabilidade Social Externa advêm de indicadores compulsórios, isto é, do cumprimento das obrigações legais.

Os indicadores ambientais revelam os recursos aplicados no meio ambiente. No Balanço Social, são subdivididos em investimentos relacionados com a produção, ou seja, são ações ambientais visando minimizar possíveis riscos causados ao meio ambiente, em decorrência do processo de industrialização e investimentos em programas externos que são projetos gerenciados pela empresa, de forma voluntária, a fim de proporcionar um meio ambiente sustentável, ao longo do tempo.

Esta área recebeu o montante de $\mathrm{R} \$ 4,4$ milhões, $1,17 \%$ em média do total de investimentos sociais investido pela empresa, durante os exercícios de 2001, 2002 e 2003.

Seguindo a tendência dos indicadores já analisados anteriormente, do total investido na área ambiental 99,5\% estão relacionados com a produção da empresa, tendência evidenciada em sua política ambiental e determina a preocupação, quase que exclusiva da organização em proteger somente o meio ambiente local dos riscos ambientais oferecidos pelo processo de industrialização da empresa.

Finalizando a análise dos investimentos realizados nas duas áreas da Responsabilidade Social (interna e externa), conclui-se que, do montante total investido ( $\mathrm{R} \$ 382,0$ milhões), R \$ 301,4 milhões (78,90\%, em média) são investimentos de caráter compulsório - encargos sociais, participação nos lucros e resultados e tributos, caracterizando, somente, o cumprimento do patamar inicial da Responsabilidade Social.

Para análise dos indicadores do valor adicionado serão utilizados os indicadores de análise da Demonstração do Valor Adicionado - DVA proposto por DALMÁCIO (2004).

O Balanço Social divulga apenas o valor total adicionado a distribuir, assim como o porcentual da participação de seus usuários - colaboradores, governo, terceiros e acionistas.

Durante os anos de 2001, 2002 e 2003, foi gerado um montante de riqueza na ordem de $\mathrm{R} \$ 325.567 .000, \mathrm{R} \$$ 392.690.000 e $\mathrm{R} \$ 316.795 .000$, respectivamente.

Os colaboradores foram os que mais se beneficiaram, com uma média anual de 52,86\% do total distribuído.

O governo, que havia recebido $15 \%$ e $17 \%$ nos anos de 2001 e 2002, respectivamente, teve um considerável aumento em sua participação no ano de 2003 - 28\%, evidenciando um possível aumento na carga tributária, revelado, de certa forma, quando da análise dos indicadores sociais, devido ao fato de a grande maioria dos investimentos terem sido de caráter compulsório (encargos sociais e tributos).

Os acionistas tiveram uma redução abrupta em sua participação, no exercício de 2003, passando de 14\% (2002) para 3\%. Tal redução, pode ter sido reflexo do aumento da carga tributária revelada no parágrafo anterior.

Depreende-se, dos percentuais de retenção do valor adicional apresentado - 1,30\%, 4,78\% e $0 \%$, para os exercícios de 2001, 2002 e 2003, respectivamente, que a empresa não vem agregando grande parcela de sua riqueza gerada, ao seu próprio capital. Se por um lado esta política beneficia as partes interessadas (colaboradores, governo, terceiros, e acionistas) com uma maior participação na distribuição do seu valor adicionado total, podendo, com isso, até atrair mais investidores externos, por outro, pode deixar a empresa desprovida de capital para futuros investimentos. Portanto, deve-se estudar o custo-benefício das alternativas.

\section{ANÁLISE DOS INDICADORES DE CARÁTER SOCIAL}

Para a análise deste item, são considerados indicadores de caráter social os do corpo funcional e as informações relevantes quanto ao exercício da cidadania empresarial, exceto os dados referentes ao valor adicionado, analisados em conjunto com os indicadores de caráter econômico.

A empresa, durante o período analisado, operou em média com 15.390 colaboradores em seu corpo funcional, sem que houvesse grandes variações nos números apresentados. Em relação ao seu quadro funcional, destaca-se um aumento de 1.701 colaboradores em 2001 e a renovação de, aproximadamente, um terço de seu quadro em 2003.

As normas do IBASE consideram a relação entre a maior e a menor remuneração, o quociente absoluto entre ambas. A evolução histórica deste item - 24,9; 22,44 e 15,26; respectivamente, para os exercícios de 2001, 2002 e 2003 mostra que a política salarial adotada pode estar levando a uma melhor distribuição de renda. Contudo, as informações obtidas sobre a folha de pagamento da empresa não foram suficientes para uma análise mais precisa deste indicador.

Entretanto, há de se investigar se a queda acentuada em 7,18 pontos apresentada na relação entre a maior e a menor remuneração, de 2002 para 2003, possui alguma relação com a renovação do quadro funcional ocorrida no mesmo período e apresentada no parágrafo anterior.

Os indicadores do corpo funcional ainda nos revelam que foram investidos em média $\mathrm{R} \$ 218,00, \mathrm{R} \$ 171,00 \mathrm{e}$ $\mathrm{R} \$ 114,00$, ao ano, por colaborador, respectivamente, nos indicadores de saúde, capacitação e desenvolvimento profissional e educação. O gráfico do anexo III mostra, com mais clareza, a evolução destes indicadores. 
A partir do ano de 2003, a empresa, que antes somente sugeria, passou a exigir de seus fornecedores os mesmos padrões éticos e de Responsabilidade Social adotados por ela, contribuindo, ainda mais, para futuras certificações de seus produtos como socialmente correto.

A empresa estabeleceu como meta, para este ano, o incentivo à participação dos colaboradores e a organização de programas sociais voluntários. Agindo diretamente em ações sociais, a empresa propicia melhor divulgação e reconhecimento público de sua marca como cidadã.

$\mathrm{O}$ indicador de reclamações e críticas de consumidores é uma importante ferramenta para a medição da satisfação do cliente. Das 15.882 reclamações realizadas nos anos de 2002 e 2003, somente 17 foram através de vias judiciais, embora o número tenha aumentado em $80,85 \%$, de um ano para o outro, todas foram resolvidas, mostrando não só o empenho da empresa em resolver os problemas como também um eficiente sistema de ouvidoria.

\section{CONCLUSÕES}

Segundo Grajew, presidente do Instituto Ethos de Empresas e Responsabilidade Social, a Responsabilidade Social inclui, para começar, o cumprimento das obrigações legais. É o patamar inicial. (...).

O exercício da cidadania empresarial pressupõe uma atuação eficaz da empresa em duas dimensões: a gestão da Responsabilidade Social Interna e a gestão da Responsabilidade Social Externa. (Melo Neto e Froes, 1999, p. 85)

O grau de participação dos indicadores sociais (GPIS) evidenciou que há um equilíbrio na distribuição dos recursos aplicados, mostrando que a política social da empresa procura abranger não só as áreas internas como também as externas.

Já a ralação dos indicadores sociais internos (RISI) e externos (RISE) revelou uma tendência no cumprimento, apenas, das obrigações sociais legais, uma vez que do montante investido nos indicadores sociais internos apenas 35\% foram destinados a projetos discricionários (capacitação profissional, saúde, educação, lazer, etc) e do montante investido nos indicadores sociais externos apenas 3,92\% foram aplicados diretamente em ações sociais perante a sociedade.

Portanto, os índices propostos atenderam as expectativas quanto sua eficiência na análise do Balanço Social da empresa Azaléia, visto que conseguiram identificar, através dos números gerados a partir dos quocientes aplicados que a gestão em responsabilidade social da entidade encontra-se somente no patamar inicial, revelando apenas uma tendência no cumprimento das obrigações legais.

Com isso, as empresas que optarem pela utilização deste modelo poderão dar maior transparência à sua gestão social, oferecendo aos seus Stakeholders não só os indicadores sociais de forma isolada, como é feito atualmente, mas tam- bém um relatório contendo informações que venham facilitálo no entendimento, na análise e na interpretação dos dados contidos no Balanço Social divulgado pela empresa.

Recomenda-se, para complementar este modelo, o estudo do cálculo de índices-padrão de Responsabilidade Social, os mais freqüentes nos balanços de empresas, que propicie, além da análise, a avaliação do Balanço Social analisado.

\section{REFERÊNCIAS}

ABEN ATHAR NETO, Jayme Marcos. Modelo para Analise de Programas de Responsabilidade Social: O Caso Azaléia. Dissertação de mestrado, UERJ, 2004.

ALIGLERI, Lilian Mara, BORINELLI, Benilson. Responsabilidade Social nas Grandes Empresas da Região de Londrina, 2001. http:// www.anpad.org.br

ASHLEY, Patricia Almeida, et al. Ética e Responsabilidade Social nos Negócios. Rio de Janeiro: Saraiva, 2002.

DALMÁCIO, Flávia Zóboli. Indicadores para Análise da Demonstração do Valor Adicionado. Revista Brasileira de Contabilidade $\mathrm{n}^{\circ}$ 149, 2004

HAWKINS, Denise Pires Basto Costa, COSTA, Silvia Pires Basto. Responsabilidade Social e Cidadania Empresarial: Uma Pesquisa Exploratória no Setor Supermercadista de Médio Porte de Fortaleza. 2002. http://www.anpad.org.br

IUDÍCIBUS, Sergio de; MARION, José Carlos. Manual de Contabilidade para Não Contadores. São Paulo: ed. Atlas, 1990.

MATARAZZO, Dante Carmine. Análise Financeira de Balanços: Abordagem Básica e Gerencial. São Paulo: ed. Atlas, 2003.

MELO NETO, Francisco de; FROES, César. Responsabilidade Social E Cidadania Empresarial: A Administração do Terceiro Setor. São Paulo: ed. Atlas, 2001.

Gestão Responsabilidade Social Corporativa: O Caso Brasileiro. São Paulo: ed. Atlas, 2001.

PEROTTONI, Marco Antônio. Balanço Social: Responsabilidade, Padronização e Obrigatoriedade. Revista Brasileira de Contabilidade $\mathrm{n}^{\circ} 134,2002$.

TINOCO, João Eduardo Prudêncio. Balanço Social: Balanço da Transparência Corporativa e da Concertação Social. Revista Brasileira de Contabilidade $\mathrm{n}^{\circ}$ 135, 2002.

Balanço Social: Uma Abordagem da Transparência e da Responsabilidade Social das Organizações. São Paulo: ed. Atlas, 2001. www.ibase.com.br 
